\title{
Volatile anesthetics maintain tidal volume and minute ventilation to a greater degree than propofol under spontaneous respiration
}

Xuechao Hao ${ }^{1,2}$, Mengchan Ou ${ }^{1,2}, \mathrm{Yu} \mathrm{Li}^{i^{*}}$ and Cheng Zhou ${ }^{1,2^{*}}$

\begin{abstract}
Background: Although general anesthetics depress spontaneous respiration, the comprehensive effect of general anesthetics on respiratory function remains unclear. We aimed to investigate the effects of general anesthetics on spontaneous respiration in non-intubated mice with different types and doses of general anesthetic.

Methods: Adult C57BL/6 J mice were administered intravenous anesthetics, including propofol and etomidate, and inhalational anesthetics, including sevoflurane and isoflurane in vivo at doses of 0.5-, 1.0-, and 2.0-times the minimum alveolar concentration (MAC)/median effective dose $\left(E_{50}\right)$ to induce loss of the righting reflex (LORR). Whole-body plethysmography (WBP) was applied to measure parameters of respiration under unrestricted conditions without endotracheal intubation. The alteration in respiratory sensitivity to carbon dioxide $\left(\mathrm{CO}_{2}\right)$ under general anesthesia was also determined. The following respiratory parameters were continuously recorded during anesthesia or $\mathrm{CO}_{2}$ exposure: respiratory frequency (FR), tidal volume (TV), minute ventilation (MV), expiratory time (TE), inspiratory time (TI), and inspiratory-expiratory time ratio (I/E), and peak inspiratory flow.

Results: Sub-anesthetic concentrations (0.5 MAC) of sevoflurane or isoflurane increased FR, TV, and MV. With isoflurane and sevoflurane exposure, the $\mathrm{CO}_{2}$-evoked increases in $\mathrm{FR}$, TV, and $\mathrm{MV}$ were decreased. Compared with inhalational anesthetics, propofol and etomidate induced respiratory suppression, affecting FR, TV, and MV. In 100\% oxygen $\left(\mathrm{O}_{2}\right)$, FR in the group that received propofol 1.0-times the $\mathrm{ED}_{50}$ was $69.63 \pm 33.44$ breaths $/ \mathrm{min}$ compared with $155.68 \pm 64.42$ breaths/min in the etomidate-treated group. In the same groups, FR was $88.72 \pm 34.51$ breaths $/ \mathrm{min}$ and $225.10 \pm 59.82$ breaths/min, respectively, in $3 \% \mathrm{CO}_{2}$ and $144.17 \pm 63.25$ breaths/min and $197.70 \pm 41.93$ breaths/ min, respectively, in $5 \% \mathrm{CO}_{2}$. A higher $\mathrm{CO}_{2}$ sensitivity was found in etomidate-treated mice compared with propofoltreated mice. In addition, propofol induced a greater decrease in FR, MV, and I/E ratio compared with etomidate, sevoflurane, and isoflurane at equivalent doses (all $P<0.05$ ).
\end{abstract}

Conclusions: General anesthetics differentially modulate spontaneous breathing in vivo. Volatile anesthetics increase FR, TV, and MV at sub-anesthetic concentrations, while they decrease FR at higher concentrations. Propofol consistently depressed respiratory parameters to a greater degree than etomidate.

Keywords: General Anesthetics, Spontaneous Respiration, Whole-body Plethysmograph

*Correspondence: liyu1936@163.com;zhouc@163.com

1 Departments of Anesthesiology, West China Hospital of Sichuan University, Chengdu 610041, China

Full list of author information is available at the end of the article

\section{Background}

More than 300 million major surgical procedures requiring general anesthesia or analgesics are conducted worldwide each year $[1,2]$. General anesthetics and analgesics induce respiratory depression, which is a critical issue in clinical practice, especially for sedative procedures original author(s) and the source, provide a link to the Creative Commons licence, and indicate if changes were made. The images or other third party material in this article are included in the article's Creative Commons licence, unless indicated otherwise in a credit line to the material. If material is not included in the article's Creative Commons licence and your intended use is not permitted by statutory regulation or exceeds the permitted use, you will need to obtain permission directly from the copyright holder. To view a copy of this licence, visit http://creativecommons.org/licenses/by/4.0/. The Creative Commons Public Domain Dedication waiver (http://creativeco mmons.org/publicdomain/zero/1.0/) applies to the data made available in this article, unless otherwise stated in a credit line to the data. 
requiring maintenance of spontaneous respiration [3]. Multiple studies have explored the depressant effect of opioids on respiration, but the effects of general anesthetics are not well elucidated $[4,5]$.

General anesthetics exert various clinically important actions, including hypnosis, amnesia, and immobility [6], as well as respiratory disturbance. Even though a depressant effect is a commonly suggested effect of general anesthetics, significant differences are observed in respiratory behavior between general anesthetics. Propofol depresses ventilation by affecting central chemoreceptor sensitivity, reducing the ventilatory response to hypercapnia, and reducing the ventilatory adaptation to hypoxia, even at sub-anesthetic doses [7, 8]. During dexmedetomidine infusion, respiratory frequency (FR) is significantly increased, and the overall apnea/hypopnea index is significantly decreased [9].

Volatile anesthetics, including isoflurane and sevoflurane, are preferred over intravenous anesthetics, such as propofol and etomidate, in conditions necessitating maintenance of spontaneous respiration, such as anticipated difficulties with endotracheal intubation. Both volatile anesthetics and intravenous anesthetics decrease FR, tidal volume (TV), and minute ventilation (MV) [10-13]. However, early clinical studies with small sample sizes indicated that volatile anesthetics, including enflurane, isoflurane, and sevoflurane, increase FR $[10,14]$. Multiple structures associated with respiration are affected by general anesthetics, including the ventral medulla, the retrotrapezoid nucleus (RTN), and phrenic motor neurons $[13,15]$. Uncovering the respiratoryrelated response in vivo during exposure to general anesthetics may help to identify the underlying mechanism. However, limitations exist in previous studies, including restricted study doses and time courses.

As a physical stimulant, carbon dioxide $\left(\mathrm{CO}_{2}\right)$ plays an important role in modulation of respiration by general anesthetics. Studies revealed an increase in the partial pressure of $\mathrm{CO}_{2}$ in artery $\left(\mathrm{PaCO}_{2}\right)$ after exposure to general anesthetics. The increase in FR under volatile anesthesia is considered to be a compensatory effect resulting from an elevated $\mathrm{PaCO}_{2}$ and respiratory depression $[10,14,16]$. However, lack of an increase in FR was found during intravenous anesthesia. Differences in the manipulation of neuronal processes that are sensitive to $\mathrm{CO}_{2}$ might contribute to the discrepancy in respiratory responses induced by volatile versus intravenous anesthetics. Even so, the effect of general anesthetics on respiratory responses to $\mathrm{CO}_{2}$ remains unclear.

Inhaled and intravenous anesthesia are two most common approach in clinic. In this study, we chose these four classic drugs of inhaled (sevoflurane and isoflurane) and intravenous anesthetics (propofol and etomidate). The dose-related and time-related effects of the four general anesthetics on respiratory behaviors in mice were explored using whole-body plethysmography (WBP). The respiratory responses to $\mathrm{CO}_{2}$ during exposure to general anesthetics were also explored. The results of this study may encourage further research into the mechanisms underlying modulation of respiration by general anesthetics.

\section{Methods}

\section{Animals}

All protocols were approved by the Institutional Animal Experimental Ethics Committee of Sichuan University (Chengdu, Sichuan, China) in accordance with the animal care guidelines of the National Institutes of Health. Endeavors were made to minimize suffering and to reduce the number of mice used.

Experiments were performed in wild type C57BL/6 J male mice aged 12 weeks, weighing $20-25$ g. All mice were housed in standard conditions, with a 12-h light/ dark cycle and with ad-libitum access to food and water. All experiments were performed during the light cycle (from 9:00 am to 5:00 pm).

\section{Whole-body Plethysmograph}

Whole-body Plethysmograph (Buxco FinePointe Series WBP 4-site system, Data Sciences International, New Brighton, MN, USA) offers a precise, non-invasive, quantitative approach to measure respiratory parameters in conscious, freely moving animals. The system relies on a specially designed chamber in which the subject is placed and allowed to breathe freely under natural conditions, unrestrained and untethered.

The volume of the plethysmography chamber was $480 \mathrm{ml}$. A constant flow was driven by an oxygen $\left(\mathrm{O}_{2}\right)$ cylinder connected to the chamber, which ensured continuous flow at $0.5 \pm 0.1 \mathrm{~L} / \mathrm{min}$ of gas, thereby preventing $\mathrm{CO}_{2}$ accumulation. Hyperoxia and hypercapnia and/or volatile anesthetics were continuously induced/ administered into the chamber through the flow pump.

FinePointe software was used to analyze incoming data and create instant reports. The following respiratory parameters were registered: FR, TV, MV, peak inspiratory flow, inspiratory time (Ti), and expiratory time (Te). Except for FR, all measured respiratory parameters (including TV and MV) were normalized to body weight to make them comparable between mice with different body weights. One technician who was blinded to the animal groups measured the respiratory outputs in vivo, and another researcher analyzed the data. 


\section{General anesthetics and $\mathrm{CO}_{2}$ administration}

Two volatile anesthetics (sevoflurane and isoflurane) and two intravenous anesthetics (propofol and etomidate) were used in this study. According to our previous studies and studies of others [17, 18], equipotent doses for inducing loss of the righting reflex (LORR) (minimum alveolar concentration $[\mathrm{MAC}] /$ median effective dose $\left.\left[\mathrm{ED}_{50}\right]\right)$ of sevoflurane, isoflurane, propofol, and etomidate were $1.58 \%, 0.86 \%, 70 \mathrm{mg} / \mathrm{kg}$ (intraperitoneally [i.p.]), and $8.85 \mathrm{mg} / \mathrm{kg}$ (i.p.), respectively. We used doses of 0.5-, 1.0-, and 2.0-times $\mathrm{MAC} / \mathrm{ED}_{50}$ required to induce LORR. Propofol at doses of $70 \mathrm{mg} / \mathrm{kg}$, and $140 \mathrm{mg} / \mathrm{kg}$, and etomidate at doses of $8.85 \mathrm{mg} / \mathrm{kg}$, and $17.7 \mathrm{mg} / \mathrm{kg}$, were injected i.p., respectively. For inhalational anesthetics, different concentrations of sevoflurane $(0.63 \%, 1.58 \%$, and $3.16 \%)$ and isoflurane $(0.34 \%, 0.86 \%$, and $1.72 \%)$ were delivered. A sample size of 8-10 mice for each dose or concentration was used, and all mice were used only once.

Propofol and etomidate (Fresenius Kabi, Bad Homburg, Germany) were injected i.p. All mice received a similar injected volume to exclude the effects of volume variation on respiratory depression in the propofol and etomidate groups.

For sevoflurane (Abbott Pharmacology Ltd., Co., Shanghai, China) and isoflurane (North Chicago, IL, USA) administration, mice were kept in the plethysmography chamber, which comprised a gas inlet and outlet. Sevoflurane or isoflurane was applied into the chamber through the inlet, with a continuous flow of $100 \% \mathrm{O}_{2}$ at a rate of $0.5 \pm 0.1 \mathrm{~L} / \mathrm{min}$. Concentrations of sevoflurane and isoflurane were monitored in real-time using the RGM monitor (Datex-Ohmeda, Louisville, CO, USA). For control mice, the chamber was filled with $100 \% \mathrm{O}_{2}$ at a flow rate of $0.5 \mathrm{~L} / \mathrm{min}$.

As indicated by our preliminary experiments, the concentration of sevoflurane or isoflurane in the chamber was balanced after $5 \mathrm{~min}$ of delivery, which was detected at the outlet. Drug washout was achieved by suctioning the chamber and flowing fresh air into the chamber between each experiment.

\section{Behavior test}

On the day of the experiment, mice were transported to the laboratory at least $2 \mathrm{~h}$ before the start of the experiment. Prior to recording, mice were placed into the plethysmography chamber with no restriction for a minimum of $2 \mathrm{~h}$ to allow acclimatization. Mice were awake and calm during testing. Over-excited mice with a high level of locomotor activity or environmental exploration were excluded from anesthetic treatment and behavioral testing.
For control mice, $100 \% \mathrm{O}_{2}$ was applied for $30 \mathrm{~min}$. For mice exposed to anesthetic, different doses of sevoflurane, isoflurane, propofol, and etomidate (as mentioned above) were applied, respectively, with $100 \% \mathrm{O}_{2}$ for $30 \mathrm{~min}$. Then, the hyperoxic-hypercapnic experiment was conducted with gas mixtures of $3 \% \mathrm{CO}_{2}, 5 \% \mathrm{CO}_{2}$, and $7 \% \mathrm{CO}_{2}$ balanced with $100 \% \mathrm{O}_{2}(0.5 \mathrm{~L} / \mathrm{min})$. In the time-course experiments, mice were administered three anesthetics with $100 \% \mathrm{O}_{2}(1 \mathrm{~L} / \mathrm{min})$ for $30 \mathrm{~min}$.

All experiments were performed at room temperature $\left(22{ }^{\circ} \mathrm{C} \pm 1.5{ }^{\circ} \mathrm{C}\right)$ and humidity $(58 \% \pm 5 \%)$. Calibration of the plethysmography chamber system was performed once per day before the experiment according to WBP instructions. After each recording, the chamber was cleaned thoroughly with $75 \%$ ethanol.

During the experiments, raw respiratory parameters were continuously recorded, and average values were calculated every $2 \mathrm{~s}$. The behavioral state of mice was classified as immobile, exploring, grooming, or undefined. In practice, only data recorded during immobility was considered in the comparison, at least $15 \mathrm{~min}$ after propofol or volatile anesthetic delivery. Treatments and tests were conducted randomly on mice in different groups to preclude potential confounding factors. The behavioral test and respiratory parameter analysis were performed with independent researchers who were blinded to the study aims and protocol.

\section{Statistical analysis}

The distribution of values in each set of experiments was tested for normality using the D'Agostino-Pearson omnibus test or the Shapiro-Wilk test. Values are expressed as mean \pm standard deviation. The means among groups were compared with with one -way or two-way analysis of variance followed by Bonferroni correction for posthoc analysis. Differences among groups were considered statistically significant when $P$ was $<0.05$. Statistical analyses were performed using Prism 7.0 software (GraphPad Software, San Diego, CA, USA) and IBM SPSS Statistics 22.0 (IBM Corp., NY, USA).

\section{Results}

\section{Sub-anesthetic concentrations of volatile anesthetics increase $F R$, $T V$, and $M V$ in wild type mice}

There were no measurable differences in respiratory activity among all experimental mice when exposed to room air, $100 \% \mathrm{O}_{2}, 3 \% \mathrm{CO}_{2}$, and $5 \% \mathrm{CO}_{2}$ conditions (data not shown). During the comparison of inhalational anesthetics, mice had similar FR, TV, and MV values at baseline $(100 \%$ $\mathrm{O}_{2}$ ). Mice showed a reactive increase in FR, TV, and MV when exposed to $1 \mathrm{MAC}$ sevoflurane and isoflurane with $100 \% \mathrm{O}_{2}$ at the beginning. Mice stabilized after 10-12 min of recording. The timeline with $1 \mathrm{MAC}$ of sevoflurane and 


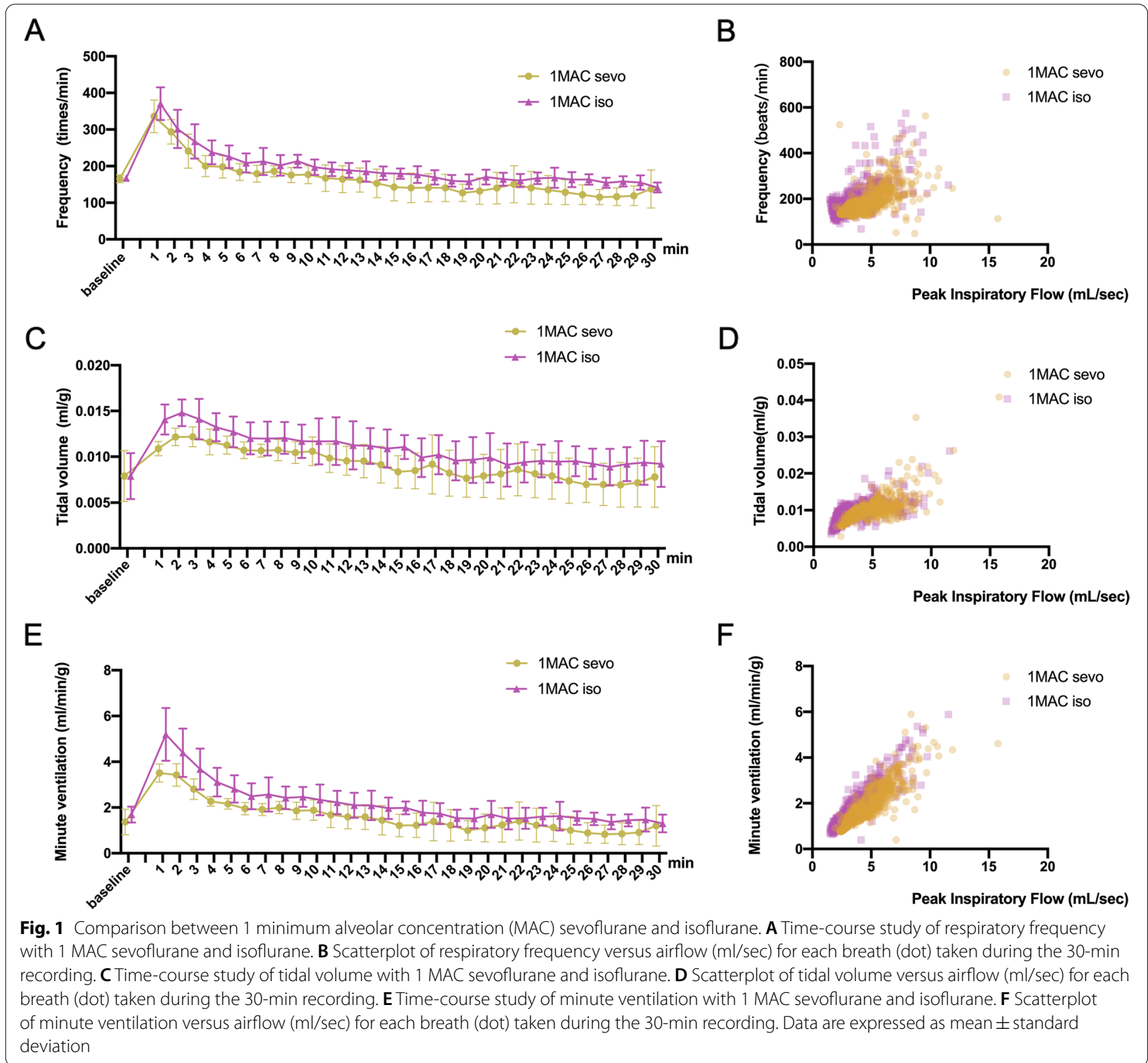

isoflurane are presented in (Fig. 1 A-F). There was no difference between two groups in FR, TV and MV.

To compare if these two inhalational anesthetics affected breathing differently, we analyzed respiratory parameters during the period when mice were stable (at 10-12 min) during the 30-min recording. Both sevoflurane and isoflurane increased the respiratory output at concentrations of 0.5 MAC and 1 MAC (Fig. 2 A-F, Fig. 3 A-F). Specifically, at concentrations of 0.5 MAC, sevoflurane and isoflurane both increased FR from $165.57 \pm 10.64$ to $245.44 \pm 31.88$ breaths/min (Fig. $2 \mathrm{~A}, P<0.001$ ) and $174.29 \pm 15.02$ to $259.41 \pm 37.62$ breaths $/ \mathrm{min}$ in $100 \% \mathrm{O}_{2}$, respectively (Fig. $3 \mathrm{~A}, P<0.001$ ). Similarly, mice exposed to $0.5 \mathrm{MAC}$ of sevoflurane and isoflurane exhibited increased ventilation under hypercapnia, as follows: sevoflurane: $3 \% \mathrm{CO}_{2}$ vs. $100 \% \mathrm{O}_{2}$ produced $\mathrm{P}$ values of $0.006,0.950$, and $<0.001$ for FR, TV, and MV, respectively, and $5 \% \mathrm{CO}_{2}$ vs. $100 \%$ $\mathrm{O}_{2}$ produced $\mathrm{P}$ values of $0.001,0.027$, and 0.403 for $\mathrm{FR}$, $\mathrm{TV}$, and MV, respectively; isoflurane: $3 \% \mathrm{CO}_{2}$ vs. $100 \%$ $\mathrm{O}_{2}$ produced $\mathrm{P}$ values of $<0.001,0.431$, and 0.001 for $\mathrm{FR}$, $\mathrm{TV}$, and MV, respectively, and $5 \% \mathrm{CO}_{2}$ vs. $100 \% \mathrm{O}_{2}$ produced $\mathrm{P}$ values of $0.004,<0.001$, and $<0.001$ for $\mathrm{FR}$, TV, and $\mathrm{MV}$, respectively. FR responses to increased $\mathrm{CO}_{2}$ were all diminished with administration of $2 \mathrm{MAC}$ sevoflurane (Fig. $2 \mathrm{D}, P<0.001$ in both $3 \% \mathrm{CO}_{2}$ and $5 \% \mathrm{CO}_{2}$ conditions) and isoflurane (Fig. $3 \mathrm{D}, P<0.001$ in both $3 \% \mathrm{CO}_{2}$ 


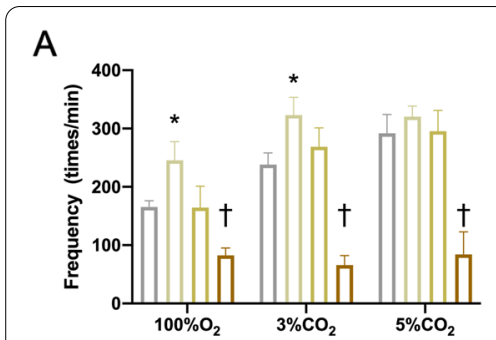

D

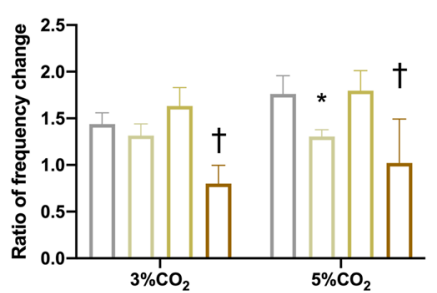

B

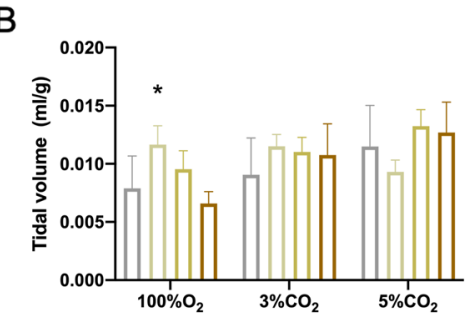

E

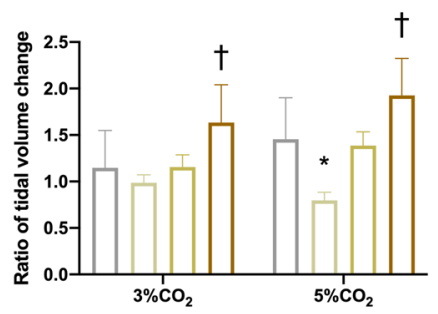

C

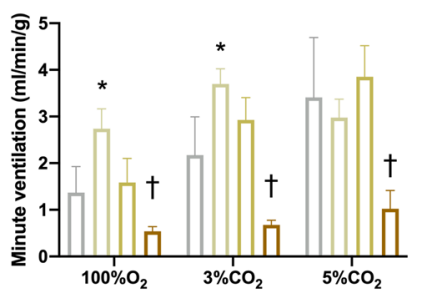

$\square$ control

$\square 0.5 \mathrm{MAC}$ sevo

$\square$ 1MAC sevo

$\square$ 2MAC sevo

$F$

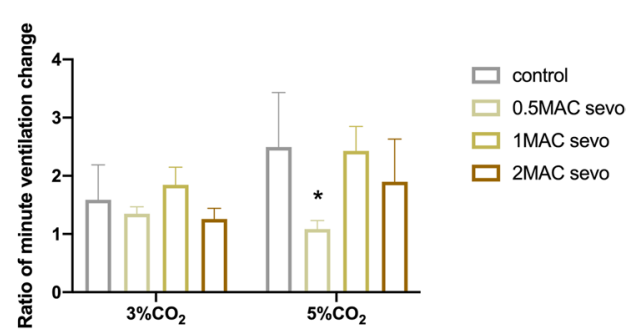

Fig. 2 Effect of sevoflurane on respiratory function in a dose-dependent manner in vivo. A-C Change in respiratory frequency (A), tidal volume (B), and minute ventilation $(\mathbf{C})$ in the control group and with three doses of sevoflurane (0.5 MAC, 1 MAC, and 2 MAC) are depicted. D-F Carbon dioxide induced change ratios in respiratory frequency (D), tidal volume (E), and minute ventilation (F) in the control group and with three doses of sevoflurane (0.5 MAC, $1 \mathrm{MAC}$, and $2 \mathrm{MAC}$ ) are depicted. Data are expressed as mean \pm standard deviation. ${ }^{*}$, \#, + indicate that there were significant differences compared with control in 0.5 MAC, $1 \mathrm{MAC}$, and $2 \mathrm{MAC}$ groups, respectively, by two-way ANOVA $(P<0.05)$

and $5 \% \mathrm{CO}_{2}$ conditions) but the TV responses were all increased in $2 \mathrm{MAC}$ sevoflurane (Fig. $2 \mathrm{E}, P=0.003$ in $3 \% \mathrm{CO}_{2}$ and $\mathrm{P}=0.004$ in $5 \% \mathrm{CO}_{2}$ conditions) and isoflurane (Fig. $3 \mathrm{E}, P<0.001$ in both $3 \% \mathrm{CO}_{2}$ and $5 \% \mathrm{CO}_{2}$ conditions).

\section{Propofol causes significant respiratory depression compared with etomidate}

To explore the dose-dependent effect of intravenous anesthetics on respiratory depression, we used two different concentrations of propofol and etomidate $\left(1 \mathrm{ED}_{50}\right.$ and $2 \mathrm{ED}_{50}$, Fig. $\left.4 \mathrm{~A}-\mathrm{D}\right)$. We found that compared with $1 \mathrm{ED}_{50}$, propofol depressed TV in the group exposed to $2 \mathrm{ED}_{50}(P=0.004)$ (Fig. 4 Aii). Etomidate also depressed TV at a higher dose $(P<0.001)$ (Fig. 4 Cii). Scatter plot (tidal volume vs. airflow) also showed that compared to $1 \mathrm{ED}_{50}$, breathing in $2 \mathrm{ED}_{50}$ propofol group became slow and less forceful (Fig. 4 Bii).

In mice exposed to $1 \mathrm{ED}_{50}$ of propofol and etomidate, a time-course study revealed that propofol progressively reduced FR, TV, and $\mathrm{MV}$ and stabilized after 20 min during the 30-min exposure (Fig. 5 A, B, $\mathrm{C})$. However, there was no further respiratory depression after respiration decreased to a relatively stable level (after $10 \mathrm{~min}$ ) in the group that received $1 \mathrm{ED}_{50}$ etomidate (Fig. 5 A, B, C). Compared to propofol, etomidate causes less respiratory depression in FR (Fig. 5. D) and MV (Fig. 5 F). In addition, mice that received $1 \mathrm{ED}_{50}$ etomidate showed a diminished $\mathrm{CO}_{2}$-dependent increase in FR, TV, and MV. However, mice that received $1 \mathrm{ED}_{50}$ propofol showed a significant increase in FR from $100 \% \mathrm{O}_{2}$ to $5 \% \mathrm{CO}_{2}$ (Fig. 5. D, $P=0.023$ ), but not TV (Fig. 5. E, $P=0.058$ ) or MV (Fig. $5 \mathrm{~F}$, $P=0.067)$.

\section{Inhalational anesthetics cause less respiratory depression compared with intravenous anesthetics}

Unlike with inhalational anesthetics, mice administered intravenous anesthetics cannot be accommodated in the chamber in the beginning of the experiment. Mice in the propofol and etomidate groups became hyperactive after i.p. injection outside the chamber. Thus, we compared the stable period of each general anesthetics. We found that at equivalent doses ( $1 \mathrm{MAC}$ or $\left.1 \mathrm{ED}_{50}\right)$, sevoflurane and isoflurane caused less respiratory depression compared with propofol and etomidate (Fig. 6 A- 6 L). Propofol caused significant depression in FR, TV and MV after i.p. injection when compared with sevoflurane and isoflurane (Fig. $6 \mathrm{~A}-\mathrm{C}$ ). In addition, we compared Ti, $\mathrm{Te}$, and $\mathrm{Ti} / \mathrm{Te}$ ratio among the four anesthetics. All four general anesthetics showed an increase in TE. Among them, propofol decreased the Ti/Te ratio $(P<0.001$ when compared with sevoflurane isoflurane and etomidate groups, Fig. 6D) and increased Te from $0.13 \pm 0.01 \mathrm{~s}$ to $1.00 \pm 0.31 \mathrm{~s}$ (Fig. 6K).

\section{Discussion}

In the present study, we found that sub-anesthetic concentrations of sevoflurane and isoflurane increased $\mathrm{FR}, \mathrm{TV}$, and $\mathrm{MV}$. In addition, $\mathrm{CO}_{2}$-sensitive respiratory responses were maintained to a greater degree 

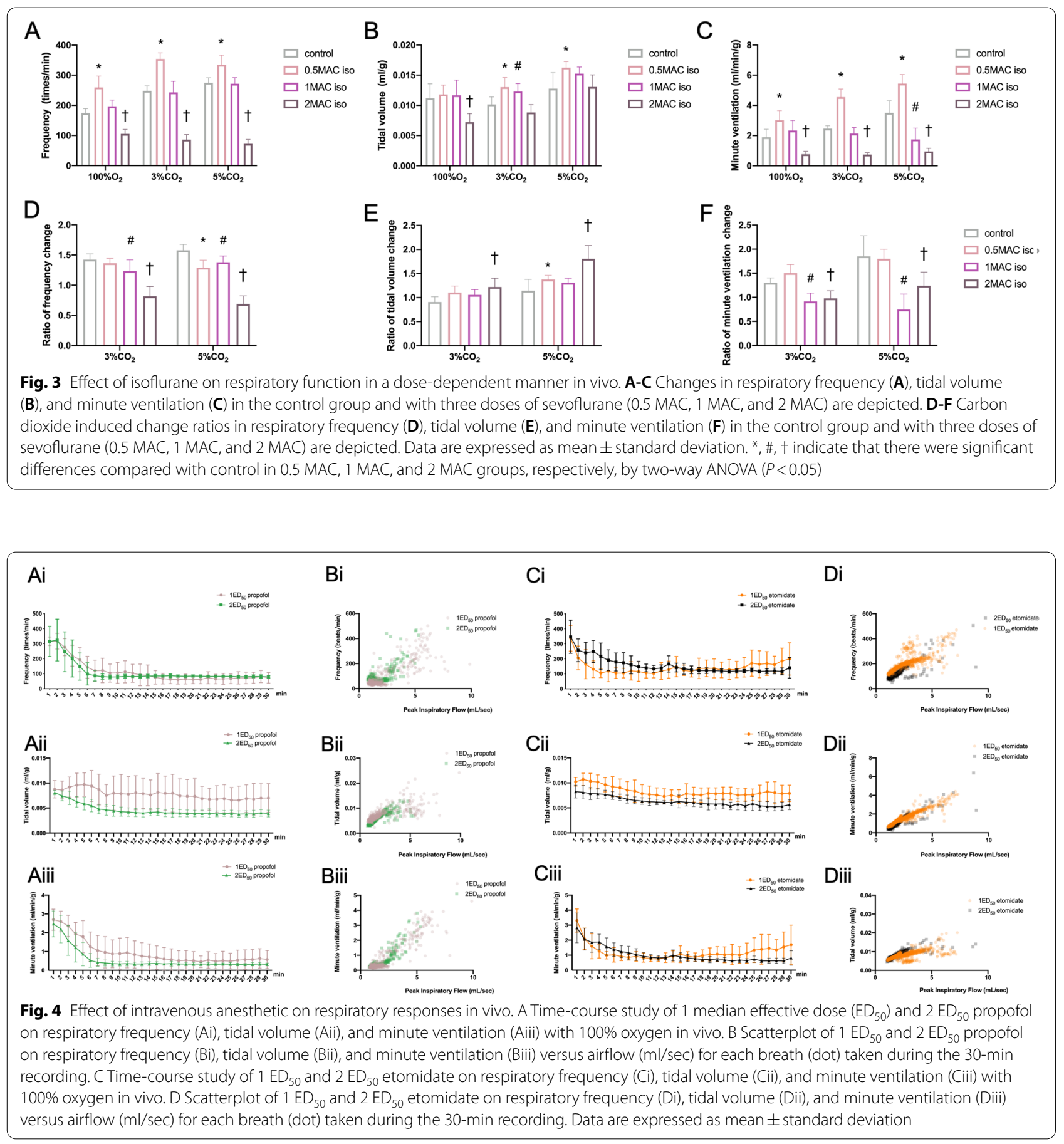

with 0.5 and 1 MAC sevoflurane/isoflurane compared with 2 MAC. Meanwhile, in contrast to the etomidate group, propofol showed a dismissed response to graded increases in $\mathrm{CO}_{2}$. A time-course analysis revealed that propofol progressively decreased TI/TE ratio during a 30-min exposure compared with sevoflurane, isoflurane, and etomidate at equivalent doses.
In this study, the respiratory response of adult mice to general anesthetics was measured with WBP. WBP is widely used for precise, non-invasive, quantitative measurement of respiratory parameters in unrestrained conditions without intubation $[19,20]$. Adult mice were administered sevoflurane, isoflurane, propofol, and etomidate in vivo at doses of 0.5-, 1.0-, and 2.0-times 


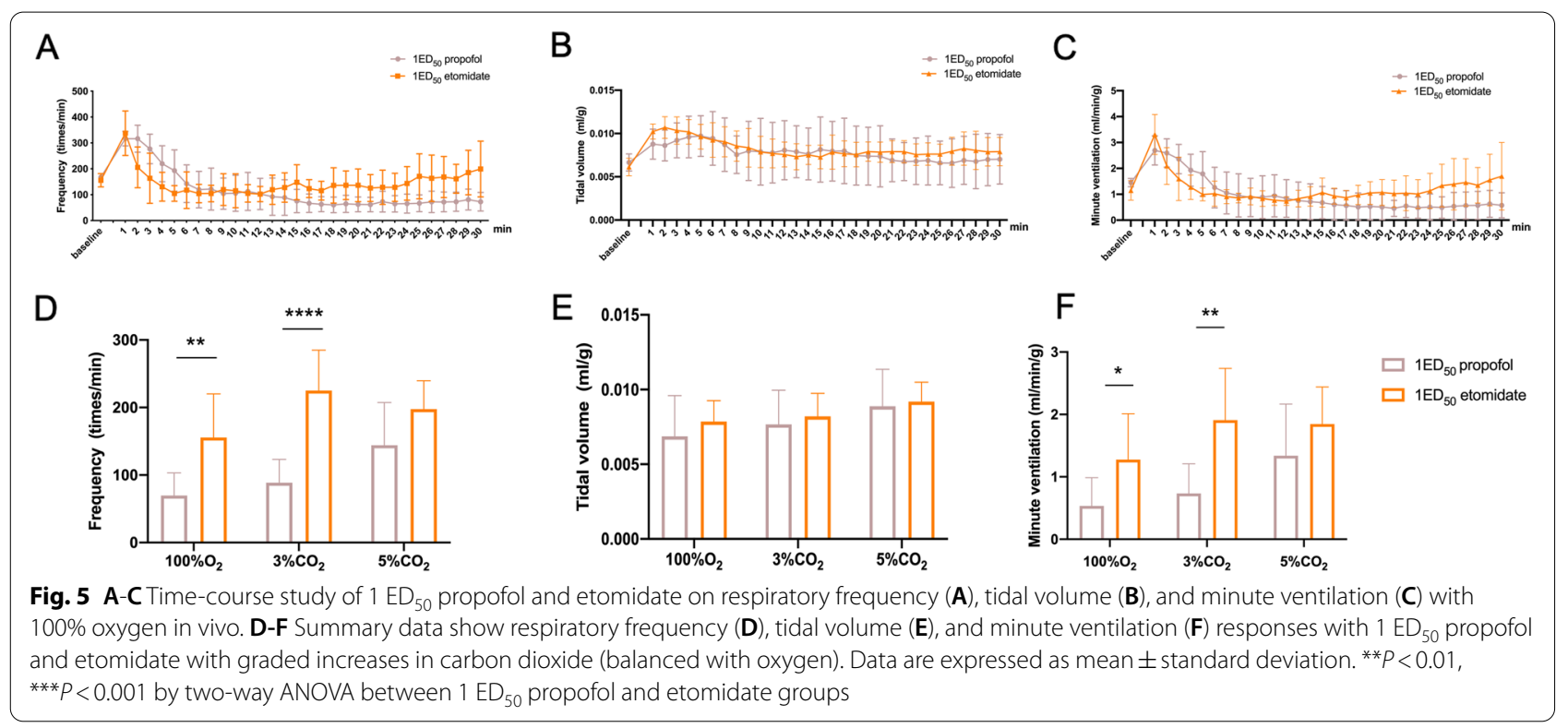

A

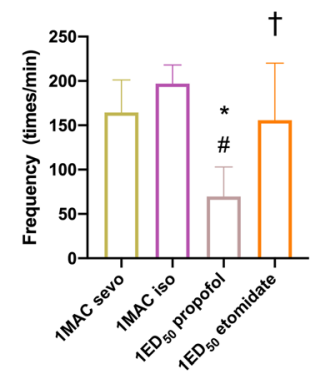

E

1MAC sevo
B

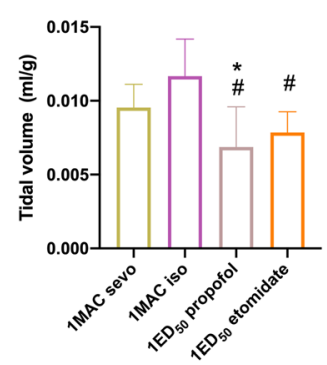

F 1MAC iso
C

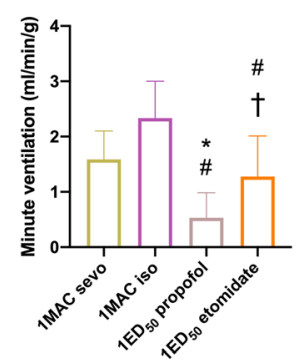

G $\quad 1 \mathrm{ED}_{50}$ propofol
D

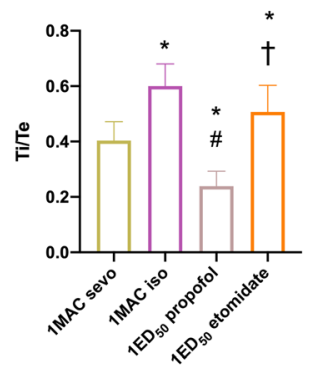

H 1ED $_{50}$ ETOMIDATE
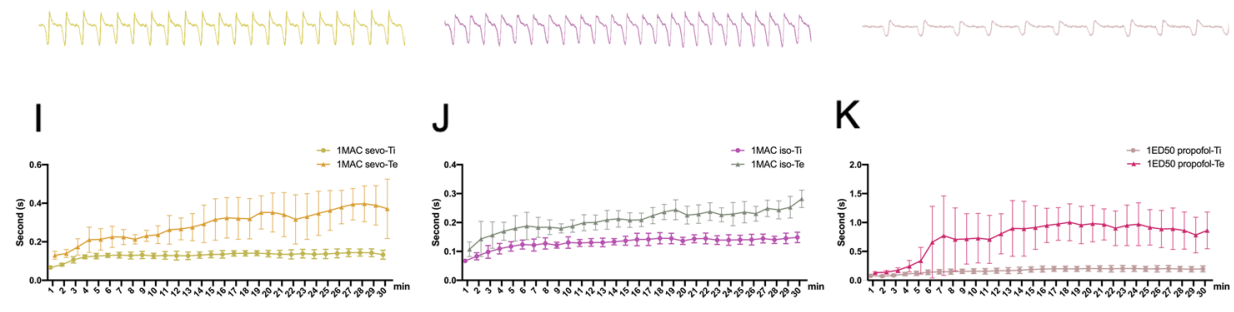

L

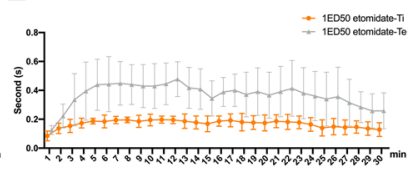

Fig. 6 A-D Summary data show respiratory frequency $(\mathbf{A})$, tidal volume $(\mathbf{B})$, minute ventilation $(\mathbf{C})$, and inspiratory time $(\mathrm{Ti}) /$ expiratory time $(\mathrm{Te})$ ratio (D) with $1 \mathrm{MAC}$ sevoflurane, $1 \mathrm{MAC}$ isoflurane, $1 \mathrm{ED}_{50}$ propofol and $1 \mathrm{ED}_{50}$ etomidate groups with $100 \%$ oxygen. $\mathbf{E}-\mathbf{H}$ Characteristic tracings of four general anesthetics on respiratory parameters in vivo. I-L Time-course study of 1 MAC sevoflurane (I), 1 MAC isoflurane (J), 1 ED 50 propofol (K) and $1 \mathrm{ED}_{50}$ etomidate $\mathbf{( L )}$ on Ti and Te with $100 \%$ oxygen in vivo. Data are expressed as mean \pm standard deviation. ${ }^{*}$, \#, † indicate that there were significant differences compared with sevoflurane, isoflurane, and propofol groups, respectively, by one-way ANOVA $(P<0.05)$

the $\mathrm{MAC}$ or $\mathrm{ED}_{50}$ required to induce LORR, which included the most commonly used dose ranges of inhalational and intravenous anesthetics. In addition, only the state of immobile respiratory parameters was observed with a sufficient duration for subsequent data analysis. The effect of general anesthesia on the $\mathrm{CO}_{2}$-sensitive respiratory response was also determined. Concentrations of sevoflurane and isoflurane were monitored in real-time using the RGM monitor to prevent drug and $\mathrm{CO}_{2}$ accumulation.

General anesthetics modulate ventilation by disturbing central chemoreceptor sensitivity, reducing the 
ventilatory response to hypercapnia, depressing metabolic ventilatory control, and inhibiting the ventilatory adaptation to hypoxia, even at sedative doses [7, 8]. In the present study, both sevoflurane and isoflurane preserved spontaneous breathing and the ventilatory response to hypercapnia at sub-anesthetic concentrations. However, higher $\mathrm{CO}_{2}$ sensitivity was not observed in mice administered 2 MAC sevoflurane/isoflurane. Although multiple sites contribute to the depressive effect of general anesthetics on respiration, the relatively selective maintenance of spontaneous breathing is poorly known. Central $\mathrm{CO}_{2}$ chemo-sensitivity in mammals is mainly mediated by Phox $2 \mathrm{~B}$-expressing neurons of the RTN, which were first known for their $\mathrm{CO}_{2} / \mathrm{pH}$ sensitivity and role in providing central chemoreceptor drive to the respiratory system [21-23]. Their $\mathrm{CO}_{2}$ sensitivity is unaffected by pharmacological blockade of the respiratory pattern generator and persists without carotid body input [22]. Volatile anesthetics cause activation of RTN neurons, which serve an important integrative role in maintaining respiratory motor activity under immobilizing anesthetic conditions [24]. Depression by propofol may be attributed to an exclusive effect within the central chemoreflex loop at central chemoreceptors. In contrast to sub-concentrations of inhalational anesthetics, the peripheral chemoreflex loop, when stimulated with $\mathrm{CO}_{2}$, remains unaffected by propofol [25].

Previous studies demonstrate that sevoflurane-induced respiratory depression is mediated by medullary respiratory and phrenic motor neurons. $\gamma$-Aminobutyric acid type $\mathrm{A}\left(\mathrm{GABA}_{\mathrm{A}}\right)$ receptors may be involved in sevoflurane-induced respiratory depression within the medulla, but not within the spinal cord $[13,26]$. Many neuronal elements within the respiratory system are inhibited by inhalational anesthetics. The mammalian pre-Bötzinger complex is an excitatory network of neurons in the medulla that is critically involved in respiration [27]. The effect of inhalational anesthetics on TASK-like channels plays a major functional role in chemosensory modulation of respiratory rhythm in the pre-Bötzinger complex [28]. However, these reported mechanisms have not yet elucidated the difference between the effects of isoflurane and sevoflurane.

In the present study, propofol displayed more obvious respiratory depression on FR, TV, and MV compared with etomidate and volatile anesthetics. Propofol at 1 ED50 exhibited rapid and significant respiratory depression approximately $3 \mathrm{~min}$ after i.p. injection compared with 1 ED50 etomidate in our study. Propofol also induced the greatest decrease in TI/TE ratio among the four general anesthetics. Propofol may cause significant airway obstruction [29]. Sedative doses of propofol cause a phase shift between abdominal and ribcage movements under spontaneous breathing without airway support (like the WBP method in our study), thereby decreasing the contribution of ribcage movement to $\mathrm{TV}$ and disturbing arterial oxygen tension [30]. It is likely that $\mathrm{GABA}_{\mathrm{A}}$ receptor-mediated hyperpolarization of neurons serves as the neuronal basis of propofol-induced respiratory depression in vivo [31,32]. Our study provides new insight into the effect of general anesthetics on respiratory behavior, but further study is needed to uncover the underlying mechanisms. One limitation of our study is that we did not include other types of general anesthetic and analgesics, such as ketamine and opioids.

\section{Conclusion}

In conclusion, the present study systematically investigated modulation of respiratory function by general anesthetics and revealed that sevoflurane and isoflurane increase respiratory parameters, even at sub-anesthetic concentrations. Propofol and etomidate depressed TV, but not FR, at higher doses. In addition, propofol induced the greatest decrease in TI/TE ratio among the four general anesthetics. These results suggest that in cases requiring maintenance of spontaneous respiration, sevoflurane or isoflurane may be a better choice than propofol or etomidate.

\section{Abbreviations \\ $\mathrm{CO}_{2}$ : Carbon dioxide; ED50: Median effective dose; FR: Respiratory frequency; $G_{A B A}: Y$-Aminobutyric acid type A; LORR: Loss of the righting reflex; MAC: Minimum alveolar concentration; $\mathrm{MV}$ : Minute ventilation; $\mathrm{O}_{2}$ : Oxygen; $\mathrm{PaCO}_{2}$ : Partial pressure of $\mathrm{CO}_{2}$ in artery; RTN: Retrotrapezoid nucleus; Ti: Inspiratory time; Te: Expiratory time; TV: Tidal volume; WBP: Whole-body plethysmography.}

\section{Acknowledgements}

We thank Yangyang Wang from West China Medical College of Sichuan University for her help in the behavioral test. We thank Emily Woodhouse, PhD, from Liwen Bianji, Edanz Editing China (www.liwenbianji.cn/ac), for editing the English text of a draft of this manuscript.

\section{Authors' contributions}

Xuechao Hao: Methodology, Formal analysis, Project administration, Writingoriginal draft. Mengchan Ou: Methodology, Funding acquisition, Supervision, Writing — review \& editing. Yu Li: Resources, Supervision, Validation. Cheng Zhou: Writing — review \& editing, Funding acquisition, Methodology. The authors read and approved the final manuscript.

\section{Funding}

This work was supported by grant No. 82001183 (to Dr. Ou) from National Natural Science Foundation of China. This work was also supported by the grant No. 2020YJ0052 (to Dr. Hao) from the Science and Technology Department of Sichuan Province; grant No. 2019-12M-5-011 (to Dr. Hao) from Medicine \& Health Innovation Program of the Chinese Academy of Medical Science and grant No. 19HXBH064 (to Dr. Ou) from Post-Doctor Research Project, West China Hospital, Sichuan University; the scientific research fund of the Science and Technology Department of Sichuan province (Grant No. 2018 SZ0113 to Dr. Hao). 


\section{Availability of data and materials}

The datasets used and/or analysed during the current study are available from the corresponding author (Yu Li) on reasonable request.

\section{Declarations}

\section{Ethics approval and consent to participate}

All protocols were approved by the Institutional Animal Experimental Ethics Committee of Sichuan University (Chengdu, Sichuan, China) in accordance with the animal care guidelines of the National Institutes of Health. The study was carried out in compliance with the ARRIVE guidelines.

\section{Consent for publication}

Not applicable.

\section{Competing interests}

The authors declare no competing interests.

\section{Author details}

${ }^{1}$ Departments of Anesthesiology, West China Hospital of Sichuan University, Chengdu 610041, China. ${ }^{2}$ Laboratory of Anesthesia \& Critical Care Medicine, Translational Neuroscience Center, The Research Units of West China-Chinese Academy of Medical Sciences, West China Hospital of Sichuan University, Chengdu 610041, China.

Received: 17 February 2021 Accepted: 28 August 2021

Published online: 06 October 2021

\section{References}

1. Vutskits $L, X i e Z$. Lasting impact of general anaesthesia on the brain: mechanisms and relevance. Nat Rev Neurosci. 2016;17(11):705-17.

2. Global, regional, and national disability-adjusted life-years (DALYs) for 333 diseases and injuries and healthy life expectancy (HALE) for 195 countries and territories, 1990-2016: a systematic analysis for the Global Burden of Disease Study 2016. Lancet. 2017;390(10100):1260-344.

3. Johnston KD, Rai MR. Conscious sedation for awake fibreoptic intubation: a review of the literature. Can J Anaesth. 2013;60(6):584-99.

4. Levitt ES, Abdala AP, Paton JF, et al. $\mu$ opioid receptor activation hyperpolarizes respiratory-controlling Kölliker-Fuse neurons and suppresses post-inspiratory drive. J Physiol. 2015;593(19):4453-69.

5. Varga AG, Reid BT, Kieffer BL, et al. Differential impact of two critical respiratory centers in opioid-induced respiratory depression in awake mice. J Physiol. 2020;598(1):189-205.

6. Eger El, Koblin DD, Harris RA, et al. Hypothesis: inhaled anesthetics produce immobility and amnesia by different mechanisms at different sites. Anesth Analg. 1997;84(4):915-8.

7. Nieuwenhuijs D, Sarton E, Teppema L, et al. Propofol for monitored anesthesia care: implications on hypoxic control of cardiorespiratory responses. Anesthesiology. 2000;92(1):46-54.

8. Nieuwenhuijs D, Sarton E, Teppema LJ, et al. Respiratory sites of action of propofol: absence of depression of peripheral chemoreflex loop by lowdose propofol. Anesthesiology. 2001;95(4):889-95.

9. Hsu YW, Cortinez LI, Robertson KM, et al. Dexmedetomidine pharmacodynamics: part I: crossover comparison of the respiratory effects of dexmedetomidine and remifentanil in healthy volunteers. Anesthesiology. 2004;101(5):1066-76.

10. Doi M, Ikeda K. Respiratory effects of sevoflurane. Anesth Analg. 1987;66(3):241-4.

11. Fee JP, Thompson GH. Comparative tolerability profiles of the inhaled anaesthetics. Drug Saf. 1997;16(3):157-70.

12. Hatch DJ. New inhalation agents in paediatric anaesthesia. Br J Anaesth 1999;83(1):42-9.
13. Kuribayashi J, Sakuraba S, Kashiwagi M, et al. Neural mechanisms of sevoflurane-induced respiratory depression in newborn rats. Anesthesiology. 2008;109(2):233-42.

14. Stuth EA, Stucke AG, Zuperku EJ. Effects of anesthetics, sedatives, and opioids on ventilatory control. Compr Physiol. 2012;2(4):2281-367.

15. Onimaru $\mathrm{H}$, Homma I. A novel functional neuron group for respiratory rhythm generation in the ventral medulla. J Neurosci. 2003;23(4):1478-86.

16. Calverley RK, Smith NT, Jones CW, et al. Ventilatory and cardiovascular effects of enflurane anesthesia during spontaneous ventilation in man. Anesth Analg. 1978;57(6):610-8.

17. Zhou C, Liang P, Liu J, et al. HCN1 Channels Contribute to the Effects of Amnesia and Hypnosis but not Immobility of Volatile Anesthetics. Anesth Analg. 2015;121(3):661-6.

18. Nikaido Y, Furukawa T, Shimoyama S, et al. Propofol Anesthesia Is Reduced in Phospholipase C-Related Inactive Protein Type-1 Knockout Mice. J Pharmacol Exp Ther. 2017;361(3):367-74.

19. Bastianini S, Alvente $S$, Berteotti C, et al. Accurate discrimination of the wake-sleep states of mice using non-invasive whole-body plethysmography. Sci Rep. 2017;7:41698.

20. Hill R, Santhakumar R, Dewey W, et al. Fentanyl depression of respiration: comparison with heroin and morphine. Br J Pharmacol. 2020;177(2):254-66.

21. Feldman JL, Mitchell GS, Nattie EE. Breathing: rhythmicity, plasticity, chemosensitivity. Annu Rev Neurosci. 2003;26:239-66.

22. Mulkey DK, Stornetta RL, Weston MC, et al. Respiratory control by ventral surface chemoreceptor neurons in rats. Nat Neurosci. 2004;7(12):1360-9.

23. Guyenet PG, Bayliss DA, Stornetta RL, Fortuna MG, Abbott SB, DePuy SD. Retrotrapezoid nucleus, respiratory chemosensitivity and breathing automaticity. Respir Physiol Neurobiol. 2009;168(1-2):59-68.

24. Lazarenko RM, Fortuna MG, Shi Y, et al. Anesthetic activation of central respiratory chemoreceptor neurons involves inhibition of a THIK-1-like background $\mathrm{K}(+)$ current. J Neurosci. 2010;30(27):9324-34.

25. Kumar NN, Velic A, Soliz J, et al. PHYSIOLOGY. Regulation of breathing by $\mathrm{CO}_{2}$ requires the proton-activated receptor GPR4 in retrotrapezoid nucleus neurons. Science. 2015;348(6240):1255-60.

26. Umezawa N, Arisaka H, Sakuraba S, et al. Orexin-B antagonized respiratory depression induced by sevoflurane, propofol, and remifentanil in isolated brainstem-spinal cords of neonatal rats. Respir Physiol Neurobiol. 2015;205:61-5.

27. Smith JC, Butera RJ, Koshiya N, et al. Respiratory rhythm generation in neonatal and adult mammals: the hybrid pacemaker-network model. Respir Physiol. 2000;122(2-3):131-47.

28. Koizumi H, Smerin SE, Yamanishi T, et al. TASK channels contribute to the $\mathrm{K}+$-dominated leak current regulating respiratory rhythm generation in vitro. J Neurosci. 2010;30(12):4273-84.

29. Shin HJ, Kim EY, Hwang JW, et al. Comparison of upper airway patency in patients with mild obstructive sleep apnea during dexmedetomidine or propofol sedation: a prospective, randomized, controlled trial. BMC Anesthesiol. 2018;18(1):120.

30. Yamakage $M$, Kamada $Y$, Toriyabe $M$, et al. Changes in respiratory pattern and arterial blood gases during sedation with propofol or midazolam in spinal anesthesia. J Clin Anesth. 1999;11(5):375-9.

31. Kashiwagi M, Okada Y, Kuwana S, et al. A neuronal mechanism of propofol-induced central respiratory depression in newborn rats. Anesth Analg. 2004;99(1):49-55.

32. Zeller A, Arras M, Lazaris A, et al. Distinct molecular targets for the central respiratory and cardiac actions of the general anesthetics etomidate and propofol. FASEB J. 2005;19(12):1677-9.

\section{Publisher's Note}

Springer Nature remains neutral with regard to jurisdictional claims in published maps and institutional affiliations. 